\title{
Canada Lynx (Lynx canadensis) Detection and Behaviour Using Remote Cameras during the Breeding Season
}

\author{
Shannon M. Crowley ${ }^{1,}{ }^{*}$, Dexter P. Hodder ${ }^{1}$, and Karl W. LARSEN ${ }^{2}$ \\ ${ }^{1}$ John Prince Research Forest, P. O. Box 2378, Fort St. James, British Columbia V0J 1P0 Canada \\ ${ }^{2}$ Department of Natural Resource Science, Thompson Rivers University, 900 McGill Road, Kamloops, British Columbia \\ V2C 0C8 Canada \\ ${ }^{*}$ Corresponding author; email: crowley@unbc.ca
} Crowley, Shannon M., Dexter P. Hodder, and Karl W. Larsen. 2013. Canada Lynx (Lynx canadensis) detection and behaviour
using remote cameras during the breeding season. Canadian Field-Naturalist 127(4): 310-318.

The efficacy of surveys in detecting Canada Lynx (Lynx canadensis) can vary considerably by geographic area. We conducted surveys using digital passive infrared trail video-cameras from January to April 2013, during the breeding season of the Canada Lynx, in the John Prince Research Forest in central British Columbia. We used snow-track surveys to test the efficacy of our camera surveys. We measured trail camera detection rates by survey week and location and we noted Canada Lynx activity and behaviours recorded by the cameras. The detection rate increased between January and April, reaching a peak of 8 Canada Lynx/100 camera-days in early April. Canada Lynx spent more time at camera sites displaying behaviours such as scent-marking and cheek-rubbing in late March. The combination of both snow-track and trail camera surveys was especially effective, with Canada Lynx detected at $77 \%$ of all monitored sites. Depending on survey objectives, it may be beneficial to conduct camera as well as other non-invasive survey methods for Canada Lynx during the breeding season, when survey efficacy and detection rates are maximized.

Key Words: British Columbia; behaviour; breeding season; Canada Lynx; Lynx canadensis; detection; non-invasive; trail cameras; snow-tracking survey; British Columbia

\section{Introduction}

Non-invasive field surveys are commonly used to assess and monitor the presence, distribution, and/or abundance of carnivores (e.g., Patterson et al. 2004; Squires et al. 2004; Rosatte 2011). These surveys are often used as the basis for management decisions and actions, such as setting harvest quotas and assigning conservation status. Effective and reliable methods of detecting individuals across a species' range are therefore needed to monitor populations and inform management decisions.

The efficacy of survey methods for Canada Lynx (Lynx canadensis) can vary considerably by geographic area (McDaniel et al. 2000; Crowley et al. 2005*; Burdett et al. 2006*; Moen and Lindquist 2006*; McKelvey et al. 2006; Squires et al. 2012), and there is currently no single survey technique that can be applied consistently and uniformly across its range. The animal's elusive nature, large spatial requirements, and dense forested habitat present several statistical and logistical challenges to the design of detection and abundance surveys. In addition, large fluctuations in populations through space and time may increase the variance in the number of Canada Lynx detected among survey plots and years and may change the effort needed for detection (Squires et al. 2012).

Trail cameras, hair snares, and snow-track surveys have all been used with mixed success to detect Canada Lynx. Hair snares have worked well in the northern boreal forest of southern Yukon and British Columbia
(McDaniel et al. 2000), but have not been very effective in other areas, such as Minnesota or Maine (Crowley et al. 2005*; Burdett et al. 2006*).

Snow-track surveys have proven to be an effective method of detecting Canada Lynx (Squires et al. 2004, 2012), but survey logistics and conditions can often make it difficult to take advantage of limited survey opportunities. This method depends on fresh snow from snowstorms, which may be infrequent; in addition, windy days, snow crusts, and melting snow can disrupt survey schedules or make it impossible to conduct snow-track surveys. Consequently, for snow tracking to be successful over large geographic areas, regular snow events and/or multiple survey crews are needed to take advantage of suitable tracking conditions. Another limitation of this technique is its reliance on the accurate reading of track sign by trained observers.

Snow tracking does not provide indisputable evidence of the presence of Canada Lynx, compared to DNA or photographic evidence. Track misidentification can be particularly problematic in areas where the ranges of the Canada Lynx and the Bobcat (Lynx rufus) overlap. Although combining snow tracking and DNA sampling for Canada Lynx has been successful in some areas (McKelvey et al. 2006), this approach requires more effort using methods that are already limited by suitable environmental conditions. Alternative or complementary field methods to snow-track surveys would be useful for the efficient and reliable monitoring of Canada Lynx populations. 
Although trail cameras are frequently used as a detection technique for many felid species (e.g., Karanth and Nichols 1998; Heilburn et al. 2003; Garrote et al. 2010), there has been limited use of trail cameras to detect Canada Lynx. The few studies that have used trail cameras have reported low detection rates compared to other survey techniques, such as snow-track surveys (Crowley et al. 2005*; Moen and Lindquist 2006*; Nielsen and McCollough 2009). The mixed success of trail cameras and other survey methods for Canada Lynx may be attributed in part to differences in survey season. Timing should be taken into consideration when surveys for Canada Lynx are conducted. Seasonal differences in the behaviour of Canada Lynx may influence detection success, as Canada Lynx may be more susceptible to attractants during different times of the year.

A uniform and standardized protocol for surveying Canada Lynx across its range would allow comparisons of populations and would be useful in informing decision-making processes regarding management and conservation. As part of a multi-species effort to monitor small- to medium-sized carnivores, we conducted trail camera surveys from mid-winter to late winter during a time period that coincides with the breeding season of the Canada Lynx (Anderson and Lovallo 2003). We used snow-track surveys to test the efficacy of our camera surveys. Our objective was to determine the detection success of trail cameras during the winter and relate that to changes in Canada Lynx activity. We hypothesized that behaviour of Canada Lynx would vary throughout the winter and that detection would be highest during the breeding season, when Canada Lynx are most susceptible to lure and bait attractants. We further describe trends in behaviour and activity and discuss the implications of our results for the type and timing of surveys for Canada Lynx.

\section{Study Area}

The research was conducted in and adjacent to the John Prince Research Forest in north-central British Columbia, Canada (Figure 1). A 16 500-ha portion of forested provincial land $45 \mathrm{~km}$ northwest of the town of Fort St. James, the John Prince Research Forest is co-managed by the University of Northern British Columbia and the Tl'azt'en Nation.

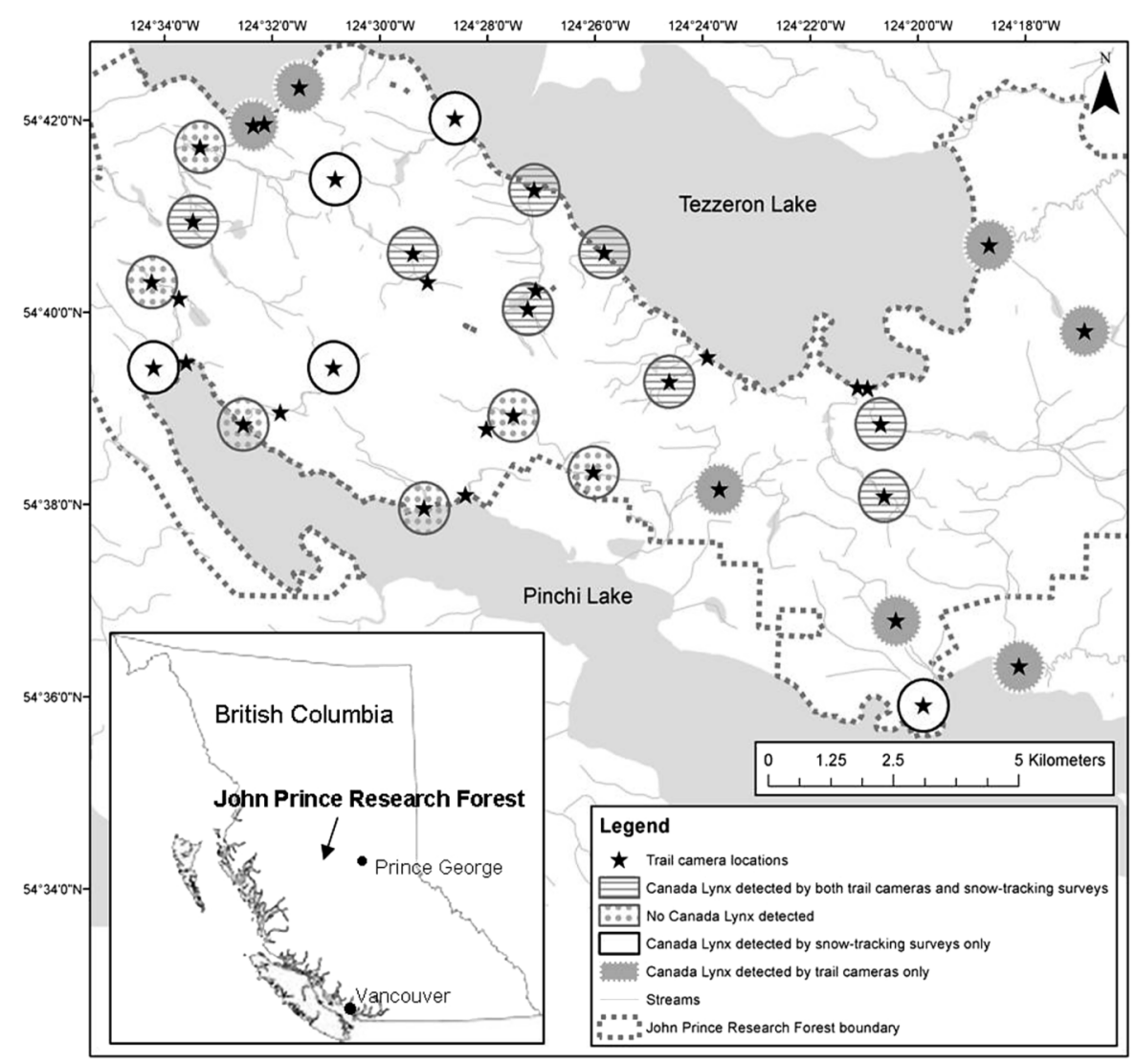

FIGURE 1. John Prince Research Forest, central British Columbia, showing trail camera locations $(n=37)$, snow-track survey zones around camera sites $>1 \mathrm{~km}$ apart $(n=26)$, and locations of Canada Lynx (Lynx canadensis) detections using trail camera and snow-track surveys, January to April 2013. 
The John Prince Research Forest is characterized by rolling terrain with low mountains $(700 \mathrm{~m}$ to $1500 \mathrm{~m}$ above sea level). It represents the northern extent of contiguous Rocky Mountain Douglas-fir (Pseudotsuga menziesii var. glauca) forests in the interior of British Columbia and is dominated by the Sub-Boreal Spruce biogeoclimatic zone (Delong et al. 1993). The area has experienced a wide variety of logging activities over the past 50 years and contains a mosaic of old and young forest (continuum from new harvest to old growth $>250$ years old) with interspersed deciduous stands. The stands have a relatively rich understory of deciduous shrubs and regenerating conifers. The research forest is traversed by many small streams that flow into either Tezzeron Lake or Pinchi Lake. Although there are many other carnivore species, the only other felid species that has been observed in the study area is the Cougar (Puma concolor), which has been observed only rarely.

\section{Methods}

\section{Trail camera surveys}

In winter 2013, digital passive infrared trail cameras (Bushnell Trophy Cam model 119467 and Bushnell Trophy Cam HD Max Model 119477, Bushnell Outdoor Products, Overland Park, Missouri) were set for two three-week sessions and one two-week session encompassing the estimated timing of the Canada Lynx breeding season (Anderson and Lovallo 2003), specifically mid-winter (23 January to 12 February), late winter ( 5 to $25 \mathrm{March})$, and end of winter (3 to 17 April).

A total of 37 cameras were set in riparian habitat, including lakeshores and streams, throughout the research forest. Twenty-six of these camera stations were spaced $>1 \mathrm{~km}$ apart (Figure 1) and were used to calculate detection rates and to make comparisons between survey techniques. Riparian corridors were chosen because of their potential use as travel corridors by a multitude of carnivore species.

At each site, a camera was set between 0.5 and $1 \mathrm{~m}$ above the snow on a tree or fallen log. Bait and lure were set up near the ground 2 to $3 \mathrm{~m}$ from the camera. The bait was a combination of salmon (Oncorhynchus nerka) paired with either American Beaver (Castor canadensis) or Moose (Alces americanus) meat suspended between 0.5 and $1 \mathrm{~m}$ above the ground. During the late-winter and end-of-winter surveys, a small diameter $\log (<15 \mathrm{~cm})$ secured in the snow with one end pointing out directly below the bait $(\sim 30$ to $40 \mathrm{~cm}$ below the bait) was added to the set. The addition of this log served as both a platform for American Mink (Neovison vison) and American Marten (Martes americana) to stand on and approach the bait as well as an additional solid object that Canada Lynx could sniff, scent-mark, and rub their faces against. Commercial mink lure (Hawbaker's Mink Lure 1, S. Stanley Hawbaker and Sons, Fort Loudon, Pennsylvania) and beaver castor were placed directly above the bait as well as on the log and ground below the bait. Cameras were checked, bait was replaced, and additional lure was added approximately midway through each session. In general, batteries and memory cards were changed between sessions.

Cameras were set to take 30 seconds of video with a 1 -second delay between video-recordings. This schedule allowed for nearly continuous recording of the time an animal was in view. The sensor level was set to normal, LED control for night vision was set to medium, and video sound recording was turned on.

\section{Snow-track surveys}

To test the efficacy of trail cameras in detecting Canada Lynx, we conducted two snow-track surveys, the first on 26 and 27 February and the second on 19 and 20 March 2013. Snow-track surveys were conducted within a circle of $500 \mathrm{~m}$ radius centered on each of the 26 camera locations that were $>1 \mathrm{~km}$ apart. Transects between 800 and $1000 \mathrm{~m}$ in length generally bisected each circle. Transect lines followed travel corridors, such as riparian streams, shorelines, and old logging roads. Surveys were conducted primarily from snowmobile but included sections traveled by snowshoe where access was difficult. Surveys were conducted 24 to 72 hours after snow had fallen to allow sufficient time for Canada Lynx movements and limit the deterioration of track quality. Every time an observer encountered a Canada Lynx track crossing the transect, the location of the track crossing was recorded on a hand-held GPS (Garmin Rino 530HCx, Olathe, Kansas).

\section{Video data collection}

While reviewing video-recordings, we noted the date, time, and location of Canada Lynx detections, the number of video-recordings made per visit, the number of individual Canada Lynx, and whether the videorecording was made during the nighttime or the daytime. Three different behaviours were recorded by the cameras: lure sniffs (a Canada Lynx approached and directly sniffed the lure/bait), scent markings (a Canada Lynx urinated on the lure/bait), and cheek rubs (a Canada Lynx rubbed its cheeks on lure/bait). From these data, we calculated the following performance metrics: detection rate by survey period and week (number of Canada Lynx detections per 100 cameradays) and detection rate by location (proportion of sites where a Canada Lynx was detected).

Spearman's rank correlations were calculated for the number of Canada Lynx detections per 100 cameradays and the week and for the proportion of sites where a Canada Lynx was detected and the week. In all analyses, the level of significance was $P=0.05$. A detection was considered independent if it was $>1$ hour since the previous visit by a Canada Lynx to the site. Visits were recorded as a single detection regardless of the number of Canada Lynx present in a group during that visit. We then compared survey detection rates by location 
obtained from the cameras and the snow-track surveys to investigate the efficacy of trail cameras in detecting Canada Lynx.

To describe the behavioural characteristics of Canada Lynx through time, we included data from all 37 cameras. As a measure of time spent at a site, we used the number of 30 -second video-recordings made of each detection to investigate changes in the length of visits during the winter (i.e., a detection could be composed of one video-recording or several video-recordings, depending on how long the Canada Lynx spent at the site during a single visit).

We also examined the time of day that Canada Lynx were detected at camera sites. We calculated the percentage of diurnal, nocturnal, and crepuscular visits determined visually from video-recording sequences. Nocturnal visits were defined as video-recordings where the infrared light was triggered at night. Diurnal visits occurred when the infrared light did not turn on and the video was recorded in daylight. Lastly, crepuscular visits were defined as a time period when the infrared light turned on in semi-light conditions. Using the time stamp on each video-recording, we further investigated when visits occurred by separating the 24hour day into eight 3 -hour segments. We used a $\chi^{2}$ test $(P=0.05)$ to determine whether visits by Canada Lynx differed by time of day.

Lastly, as an index of breeding activity, we investigated the relative number of Canada Lynx behaviours observed at sites and how that changed throughout the winter. We calculated the number of Canada Lynx behaviours per 100 detections to measure changes in activity during the season.

\section{Results}

Trail camera surveys

The 26 trail cameras used to calculate detection rates recorded a total of 39 Canada Lynx visits (Table 1). These cameras worked properly $97 \%$ of the time, providing a total of 1204 working camera-days. Analogous data for the total set of 37 cameras was 48 Canada Lynx visits over 1653 working camera-days (93\% of total possible camera time). Camera failures were primarily the result of the sensor level being set on high and depleting the batteries or filling the memory cards.

The number of Canada Lynx detected per 100 camera-days increased for each survey period later in the winter, with 1, 3, and 7 Canada Lynx detected per 100 camera-days for the mid-winter, late-winter, and endof-winter survey periods, respectively (Table 1 ). The number of Canada Lynx detected each week also showed an increasing trend, to a seasonal high of 8 Canada Lynx detected per 100 camera-days in the final week of the survey (10-16 April) $(r=0.92, P=0.011)$ (Table 1). The percentage of sites at which Canada Lynx were detected during each survey period increased throughout the winter, finishing with a high of $36 \%$ in the week of $10-16$ April and a total of $58 \%$ for all weeks combined $(r=0.89, P=0.003)$ (Table 1).

\section{Canada Lynx behaviour}

Although there was overlap in the confidence intervals, the average number of video-recordings made during each Canada Lynx visit was highest during the weeks in the second half of March (12-25 March) (Figure 2). Visits by Canada Lynx to camera sites throughout the entire season averaged $46 \%, 48 \%$, and $6 \%$ of diurnal, nocturnal, and crepuscular visits, respec-

TABLE 1. Detection rates and working camera-days for trail camera surveys of Canada Lynx (Lynx canadensis) in the John Prince Research Forest in central British Columbia, January to April 2013.

\begin{tabular}{|c|c|c|c|c|c|c|c|}
\hline Survey & $\begin{array}{l}\text { Start } \\
\text { date }\end{array}$ & $\begin{array}{l}\text { End } \\
\text { date }\end{array}$ & $\begin{array}{c}\text { No. of } \\
\text { Canada } \\
\text { Lynx } \\
\text { detected }\end{array}$ & $\begin{array}{c}\text { Camera- } \\
\text { days }\end{array}$ & $\begin{array}{c}\text { No. of } \\
\text { Canada Lynx } \\
\text { detected/100 } \\
\text { camera-days }\end{array}$ & $\begin{array}{c}\text { No. of } \\
\text { Camera sites } \\
\text { visited by } \\
\text { Canada Lynx } \\
(n=26)\end{array}$ & $\begin{array}{c}\text { Percentage of } \\
\text { camera sites } \\
\text { visited by } \\
\text { Canada Lynx } \\
(\%)\end{array}$ \\
\hline \multicolumn{8}{|l|}{ Mid-winter } \\
\hline & 23 January & 29 January & 1 & 112 & 1 & 1 & 4 \\
\hline & 30 January & 5 February & 2 & 154 & 1 & 2 & 8 \\
\hline & 6 February & 12 February & 0 & 154 & 0 & 0 & 0 \\
\hline Total & 23 January & 12 February & 3 & 420 & 1 & 3 & 12 \\
\hline \multicolumn{8}{|l|}{ Late winter } \\
\hline & 5 March & 11 March & 3 & 182 & 2 & 3 & 12 \\
\hline & $12 \mathrm{March}$ & $18 \mathrm{March}$ & 5 & 180 & 3 & 4 & 15 \\
\hline & 19 March & 25 March & 5 & 80 & 6 & 3 & 12 \\
\hline Total & 5 March & 25 March & 13 & 442 & 3 & 6 & 23 \\
\hline \multicolumn{8}{|l|}{ End of winter } \\
\hline & 3 April & 9 April & 9 & 173 & 5 & 8 & 31 \\
\hline & 10 April & 16 April & 14 & 169 & 8 & 9 & 35 \\
\hline Total & 3 April & 16 April & 23 & 342 & 7 & 13 & 50 \\
\hline Total all surveys & & & 39 & 1204 & 3 & 15 & 58 \\
\hline
\end{tabular}




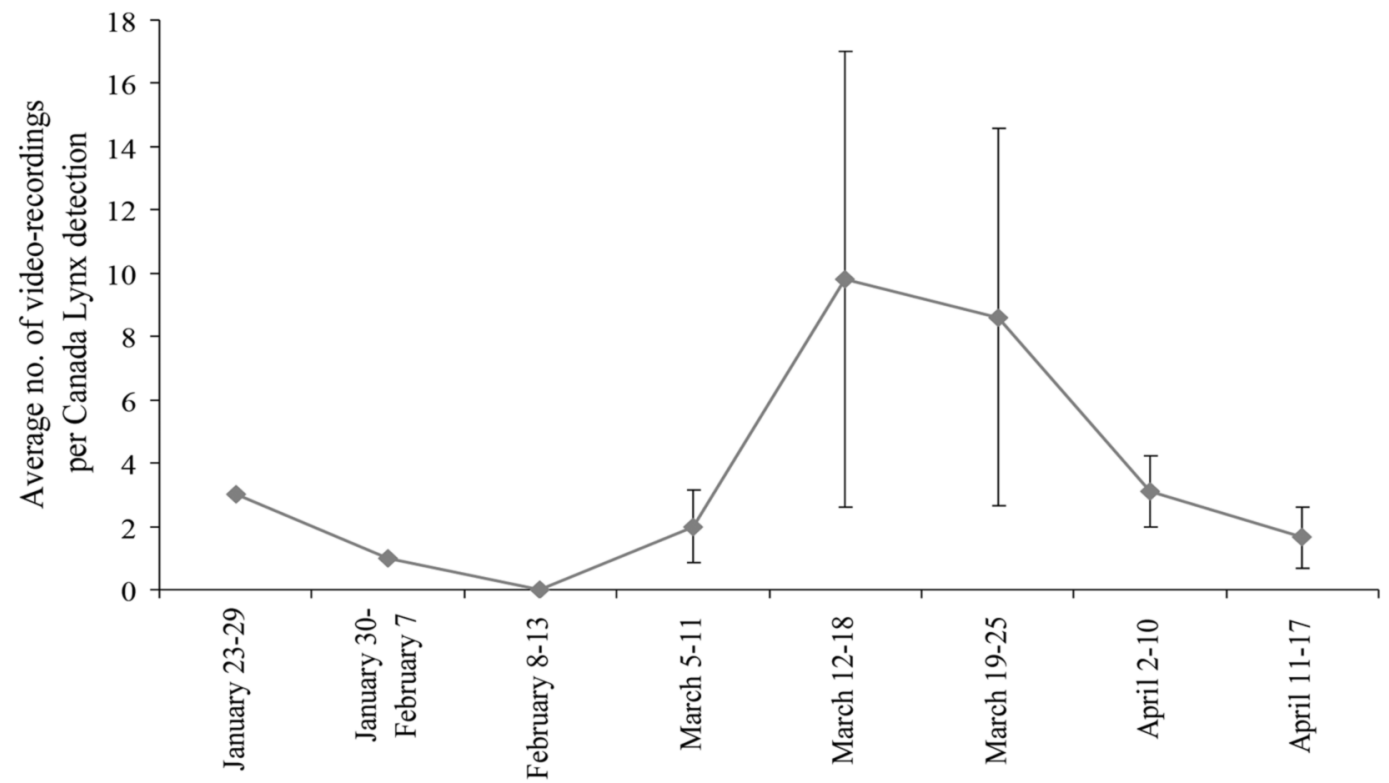

FIGURE 2. Average number of 30-second video-recordings ( \pm SE) made of each Canada Lynx (Lynx canadenis) visit $(n=48)$ by trail cameras in the John Prince Research Forest in central British Columbia, January to April 2013.

tively. Further breakdown in timing of visits (3-hour time periods) showed there was no correlation between Canada Lynx visits and time of day $\left(\chi_{6}^{2}=5.7, P=0.5\right)$. Although not significant, the highest proportion of Canada Lynx visits (22\%) occurred in the late afternoon, from 1500 to 1800 (Figure 3). All 5 Canada Lynx detections in which $>1$ individual (2-4) were recorded on video were observed between 9 March and 5 April 2013.
Cheek-rubbing behaviour was at its highest from early March to early April (5 March-9 April), with a peak in late March (Figure 4). Scent-marking behaviour remained high from mid-March to early April (12 March-9 April) before decreasing again in mid-April (10-16 April). Canada Lynx directly approached and sniffed the lure/bait when visiting a site frequently throughout the majority of the survey; however, the percentage of visits with this behaviour decreased in

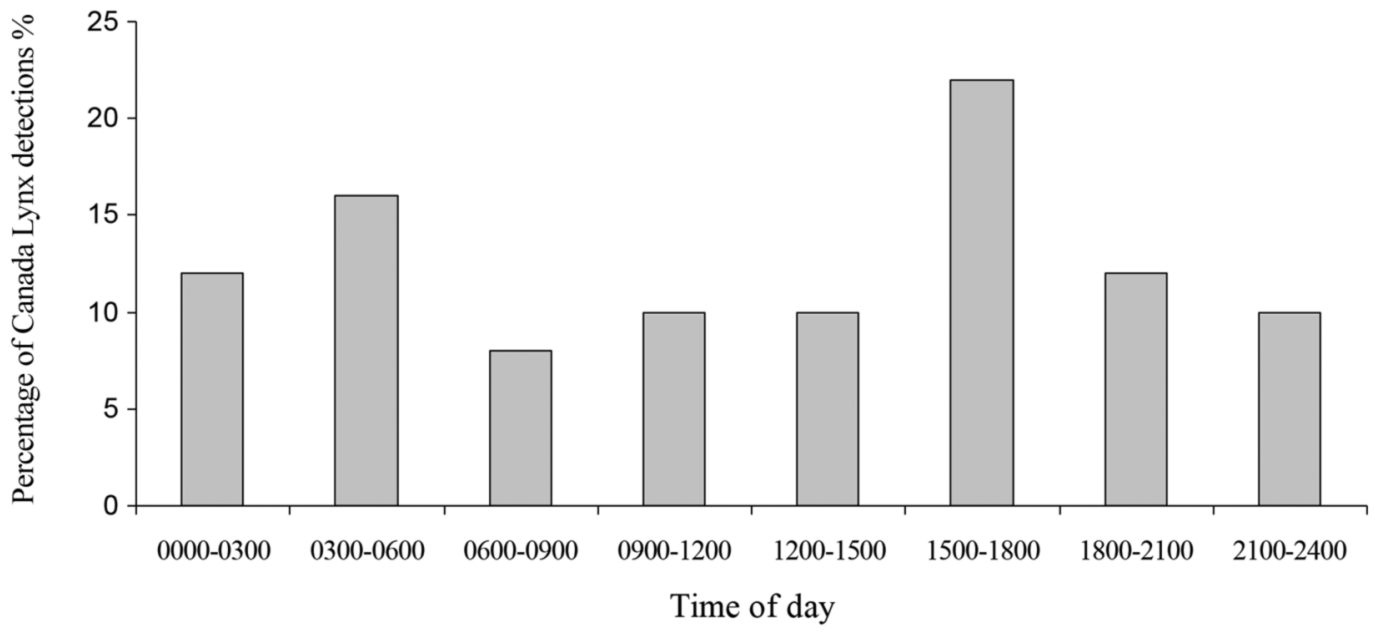

FiguRE 3. Proportion of Canada Lynx (Lynx canadensis) visits $(n=48)$ by time of day (all sites combined) recorded by trail cameras in the John Prince Research Forest in central British Columbia, January to April 2013. 


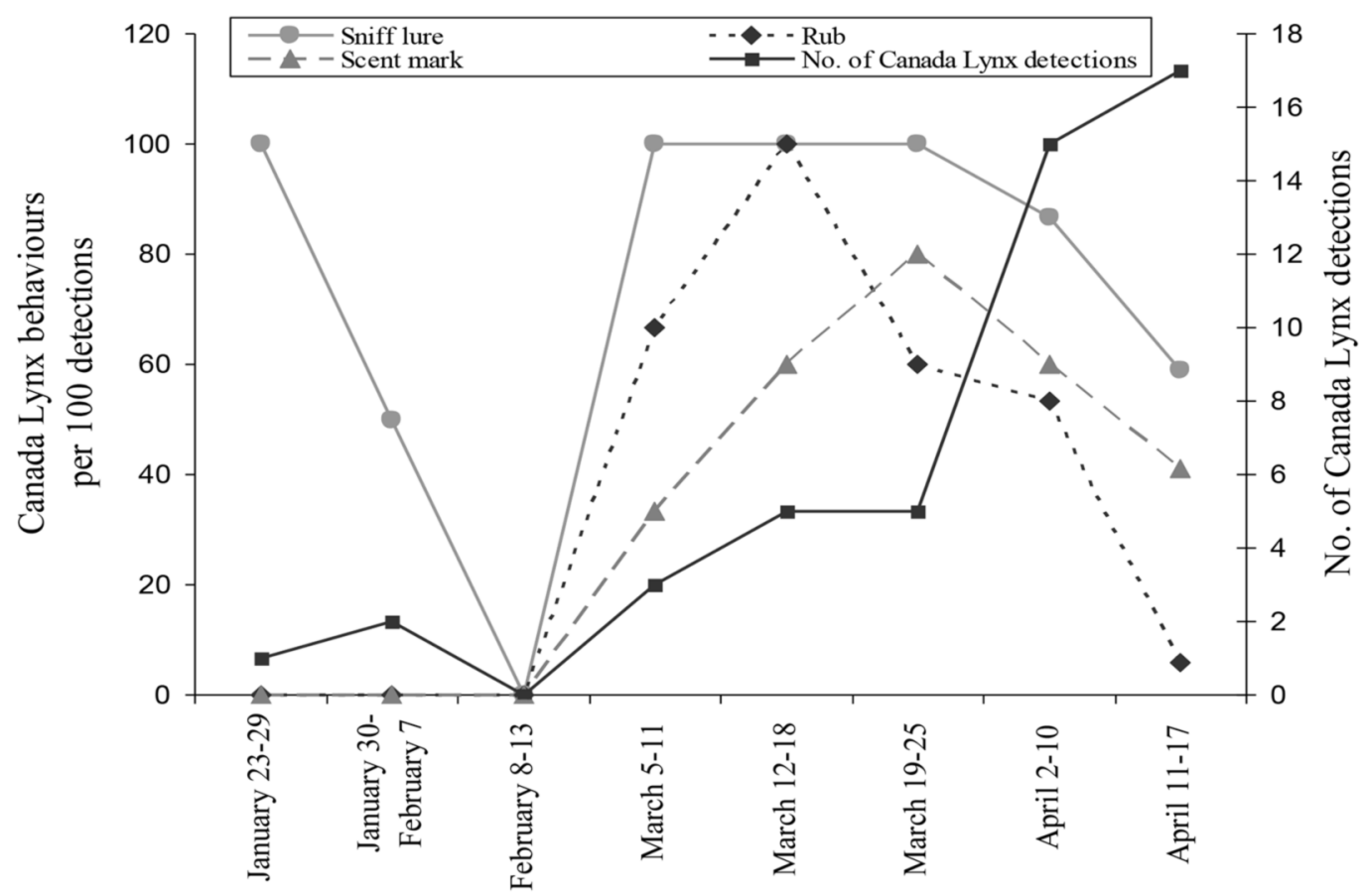

FIGURE 4. Number of detections of Canada lynx (Lynx canadensis) $(n=48)$ and behaviours per 100 detections recorded by trail cameras $(n=37$ sites $)$ in the John Prince Research Forest in central British Columbia, January to April 2013.

each of the last two weeks of the survey, from 2 April to 16 April.

\section{Snow-track surveys}

The tracks of Canada Lynx were found during snowtrack surveys in $50 \%$ of the buffer zones around camera sites $(38 \%$ of zones in the track survey on 26 and 27 February and $46 \%$ of zones in the track survey on 19 and $20 \mathrm{March}$ ). The animals were detected by trail cameras at $58 \%$ of the sites (Figure 1). Combining the data from both snow-track surveys and the trail cameras, Canada Lynx were detected at $77 \%$ of all monitored sites. Although the number of Canada Lynx detected on the snow-track surveys and by the trail cameras was similar, the site locations differed. Canada Lynx were detected on track surveys and by trail cameras at $31 \%$ of sites ( 8 of 26), by track surveys only at $19 \%$ of sites (5 of 26), and by trail cameras only at $27 \%$ of sites ( 7 of 26).

\section{Discussion}

These results have implications not only for the use of trail cameras but also for any survey technique used to detect Canada Lynx. Differences in detection rates between seasons could lead to misinterpretation of survey results, which are critical to management decisions and actions. Although mark-recapture and occupancy models can account for temporal biases associated with detection rates, confidence in model inputs improves if the probability of detection increases. An understanding of an animal's ecology and how it influences seasonal detection rates is needed to reliably interpret the results of wildlife surveys. This information can inform study designs and protocols to ensure that surveys are conducted during the most appropriate and efficient time periods.

The detection rates for each survey period in this study (mid-winter, late winter, and end of winter) showed considerable variation (from 1 to 7 Canada Lynx detected per 100 camera-days), with the higher rates being notably greater than rates reported by surveys in other areas. The only peer-reviewed published study using trail cameras for Canada Lynx reported a detection rate that was lower than camera surveys for other felid species (2 Canada Lynx detected per 100 camera-days) (Nielsen and McCollough 2009). Unpublished reports of camera surveys for Canada Lynx populations in Maine and Minnesota reported even lower detection rates, with 1 Canada Lynx/100 cameradays (Crowley et al. 2005*) and zero detections in 512 camera-days (Moen and Lindquist 2006*), respectively. Compared to the Bobcat (the only other North American felid of similar size whose range overlaps the range of the Canada Lynx), our highest detection rates were greater than or equal to other studies (4 to 7 Bobcats/100 camera-days) (see Harrison 2006 and Heilbrun et al. 2006). In Vermont, Bobcats were detect- 
ed at only $5.4 \%(3 / 56)$ of camera sites in a total of four survey weeks (Long et al. 2007).

One explanation for the high detection rate in this study is that surveys using trail cameras or hair snares for Canada Lynx are often conducted in the late summer and fall (McDaniel et al. 2000; Burdett et al. 2006*; Nielsen and McCollough 2009). Throughout the United States, the National Lynx Detection Protocol was deployed primarily in the fall using hair snare grids set out in areas with known or potential Canada Lynx populations (Burdett et al. 2006*). Although there have been limited survey efforts during portions of the winter season (Crowley et al. 2005*; Burdett et al. 2006*; Moen and Lindquist 2006*), surveys for Canada Lynx using trail cameras have not been conducted during the breeding season with the survey intensity and duration used in this study.

Canada Lynx generally breed in March and April throughout their range; however, the exact timing in different regions is not well understood (Anderson and Lovallo 2003). In Maine, the success of trapping Canada Lynx in cages typically increases during the winter as the season progresses from January to March (SMC, personal observation). In addition, hair-trapping sessions for Eurasian Lynx (Lynx lynx) have been more successful during a time period that coincides with their breeding season (Schmidt and Kowalczyk 2006).

The increase in detection rates over the course of the current study was likely due to the onset and peak of breeding activity. As the season progressed from January through March, the Canada Lynx were not only detected more often by camera, but they spent more time at camera sites scent-marking and cheek-rubbing.

Our results are especially relevant to surveys that rely on the cheek-rubbing behaviour of Canada Lynx to collect hair samples on hair snares. Cheek-rubbing behaviour remained high from early March to early April, with lower levels both before and after this time period. Detection probabilities determined from these data would most likely increase if hair-snare surveys were conducted during the time period that coincides with the Canada Lynx breeding season. Mark-recapture surveys that rely on the re-sighting of marked individuals by cameras might also benefit from being conducted during this time of the year, especially in mid-March to late March, when Canada Lynx spent more time at camera sites. Increased time in front of the camera provides additional opportunities for the identification of individuals using unique natural or human-made markings.

Although detection rates were highest in mid-April, Canada Lynx spent little time during this period at the camera sites performing cheek-rubbing or scentmarking behaviour. One explanation for this pattern of visitation may be a combination of seasonal changes in Canada Lynx ecology that include the end of breeding activity, the break-up of the previous year's family groups, and the start of dispersal (Anderson and Loval- lo 2003). In contrast to the previous few weeks, all visits to camera locations during this period were made by individual animals and did not include family groups. Detections at camera sites from mid-March to early April often included groups of multiple individuals. Winter distribution patterns may be changing during this time of the year, influencing survey results. Caution should be used in interpreting results obtained during the end of winter period, when Canada Lynx detections may be influenced by a young and transient portion of the population.

At a smaller time scale, Canada Lynx were active at camera sites equally during nighttime and daytime. Although not significant, the highest amount of activity at camera sites occurred during late afternoon and early evening, similar to an activity peak in a Montana study in which Canada Lynx were equipped with motionsensitive radio-collars (Kolbe and Squires 2007). The combined measures of behaviour used in the current study provide additional insight into the seasonal and daily activity patterns of Canada Lynx that can influence the success, timing, and interpretation of detection surveys.

To address our objectives, we also determined the relative efficacy of trail cameras and snow-tracking surveys. Although we found that the number of sites with Canada Lynx detections was similar for each method, only $31 \%$ of sites with Canada Lynx detections were in both survey techniques. Additional snow-track surveys in the last week of March or early April, when camera detections were highest, might have increased our detection rates. Snow-track surveys during this time period, however, were not a possibility because of poor tracking conditions. Also, our study generated comparisons on a small spatial scale, relative to the spatial requirements of Canada Lynx. If we were to increase our spatial scale, the detection success with both techniques would likely increase. For example, if we lay a $5 \mathrm{~km}^{2}$ grid over our study site, $80 \%$ of the grid cells (8 of 10) have Canada Lynx detections from both snow-track surveys and trail cameras and $100 \%$ have detections from one of these techniques. Even at the smaller spatial scale used in the surveys $\left(1 \mathrm{~km}^{2}\right)$, $77 \%$ of sites have Canada Lynx detections with at least one of the survey techniques.

Although we found that trail cameras are a viable option for surveying Canada Lynx during the breeding season, the combination of both trail cameras and snow-tracking surveys was especially effective. Trail cameras should be considered as a complementary technique to snow tracking to increase survey efficacy, maximize detection probabilities, and cross-validate survey techniques. In areas where it is difficult or impossible to conduct snow-track surveys, trail cameras may be used as an alternative.

The majority of Canada Lynx studies have occurred in the northern boreal forest or on the extreme southern edge of their range (e.g., Koehler 1990; Poole 1995; 
Slough and Mowat 1996; Vashon et al. 2008). There is therefore limited information on the ecology and status of Canada Lynx populations in central British Columbia, and we have very little information about Canada Lynx densities in the study area during the survey. Although the detection rates for Canada Lynx were high, detection rates would likely vary with fluctuations in Canada Lynx densities (Squires et al. 2012). For this reason, it is difficult to determine whether the overall detection rate in this study was a result of survey design (i.e., using riparian corridors, attractants), naturally high densities of Canada Lynx, movement of Canada Lynx into the area due to timber harvesting and habitat loss in the area surrounding the John Prince Research Forest, or a combination of any of these factors. The temporal trend in detection success observed in the study, however, is likely a product of ecological determinants in the life cycle of the Canada Lynx that would remain consistent with fluctuations in Canada Lynx densities.

Assessing the influence of temporal and spatial factors on the efficacy of detection surveys is critical to improving study designs and protocols (Zielinski and Kucera 1995). Depending on survey objectives, it may be beneficial to use trail cameras as well as other noninvasive methods to survey for Canada Lynx from early March to early April, when survey efficacy and detection rates can be expected to be at their highest.

Estimates of Canada Lynx distribution, relative abundance, and habitat selection derived from detection surveys can be misinterpreted if seasonal changes in behaviour and its influence on detection are not taken into account. Occupancy models where the probability of detection is $<1$ are used with increasing frequency to determine species distribution (MacKenzie et al. 2002; O'Connell et al. 2006; Bailey et al. 2007). Our results not only demonstrate the importance of estimating the detection probability, but also take into account the influences of seasonal variation on detection success. Incorporating such variation into study design and analysis will decrease bias and increase the power of a survey to detect spatial and temporal trends or patterns in distribution and abundance.

\section{Acknowledgements}

We would like to thank the John Prince Research Forest and the Habitat Conservation Trust Fund for funding this project. We also thank Johnny Tom for providing valuable field assistance.

\section{Documents Cited (marked * in text)}

Burdett, C., E. Lindquist, R. Moen, J. Niemi, and B. Route. 2006. National Interagency Canada Lynx Detection Survey in Minnesota, Wisconsin, and Michigan. University of Minnesota Natural Resources Research Institute Technical Report No. NRRI/TR-2006-29. University of Minnesota, Duluth, Minnesota.

Crowley, S. M., C. R. McLaughlin, A. D. Vashon, J. H. Vashon, W. J. Jakubas, J. F. Organ, and G. J. Matula, Jr. 2005. A comparison of survey techniques to detect
Canada Lynx (Lynx canadensis) in northem Maine. Unpublished report. Maine Department of Inland Fisheries and Wildlife, Bangor, Maine.

Moen, R., and E. L. Lindquist. 2006. Testing a remote camera protocol to detect animals in the Superior National Forest. University of Minnesota Natural Resources Research Institute Technical Report No. NRRI/TR-2006-28. University of Minnesota, Duluth, Minnesota.

\section{Literature Cited}

Anderson, E. M., and M. J. Lovallo. 2003. Bobcat and lynx (Lynx rufus and Lynx canadensis) Pages 758-786 in Wild Mammals of North America: Biology, Management, and Conservation. Second edition. Edited by G. Feldhamer, B. Thompson, and J. Chapman. John Hopkins University Press. 1216 pages.

Bailey, L. L., J. E. Hines, J. D. Nichols, and D. I. MacKenzie. 2007. Sampling design trade-offs in occupancy studies with imperfect detection: examples and software. Ecological Applications 17: 281-290.

Delong, C., D. Tanner, and M. J. Jull. British Columbia Ministry of Forests. 1993. A Field Guide for Site Identification and Interpretation for the Southwest Portion of the Prince George Forest Region, Crown Publications Inc., Victoria, British Columbia.

Garrote, G., R. Perez de Ayala, P. Pereira, F. Robles, N. Guzman, F. J. Garcia, M. C. Iglesias, J. Hervas, I. Fajardo, M. Simon, and J. L. Barroso. 2010. Estimation of Iberian lynx (Lynx pardinus) population in the Donana area, SW Spain, using capture-recapture analysis of camera-trapping data. European Journal of Wildlife Research 57: 355-362.

Harrison, R. L. 2006. A comparison of survey methods for detecting bobcats. Wildlife Society Bulletin 34: 548-552.

Heilbrun, R. D., N. J. Silvy, M. E. Tewes, and M. J. Peterson. 2003. Using automatically triggered cameras to individually identify Bobcats. Wildlife Society Bulletin 31: 748-755.

Heilbrun, R. D., N. J. Silvy, M. J. Peterson, and M. E. Tewes. 2006. Estimating Bobcat abundance using automatically triggered cameras. Wildlife Society Bulletin 34: 69-73.

Karanth, U. K., and J. D. Nichols. 1998. Estimation of tiger densities in India using photographic captures and recaptures. Ecology 79: 2852-2862.

Koehler, G. M. 1990. Population and habitat characteristics of lynx and snowshoe hares in north central Washington. Canadian Journal of Zoology 68: 845-851.

Kolbe, J. A., and J. R. Squires. 2007. Circadian activity patterns of Canada lynx in western Montana. Journal of Wildlife Management 71: 1607-1611.

Long, R. A., T. M. Donovan, P. Mackay, W. J. Zielinski, and J. S. Buzas. 2007. Comparing scat detection dogs, cameras, and hair snares for surveying carnivores. Journal of Wildlife Management 71: 2018-2025.

MacKenzie, D. I., J. D. Nichols, G. B. Lachman, S. Droege, J. A. Royle, and C. A. Langtimm. 2002. Estimating site occupancy rates when detection probabilities are less than one. Ecology 83: 2248-2255.

McDaniel, G. W., K. S. McKelvey, J. R. Squires, and L. F. Ruggiero. 2000. Efficacy of lures and hair snares to detect lynx. Wildlife Society Bulletin 28: 119-123.

McKelvey, K. S., J. VonKienast, K. B. Aubry, G. M. Koehler, B. T. Maletzke, J. R. Squires, E. L. Lindquist, 
S. Loch, and M. K. Schwartz. 2006. DNA analysis of hair and scat collected along snow tracks to document the presence of Canada Lynx. Wildlife Society Bulletin 34: 451455.

Nielsen, C. K., and M. A. McCollough. 2009. Considerations on the use of remote cameras to detect Canada lynx in Northern Maine. Northeastern Naturalist 16: 153-157.

O'Connell, A. F., Jr., N. W. Talancy, L. L. Bailey, J. R. Sauer, R. Cook, and A. T. Gilbert. 2006. Estimating site occupancy and detection probability parameters for mesoand large mammals in a coastal ecosystem. Journal of Wildlife Management 70: 1625-1633.

Patterson, B. R., N. W. S. Quinn, E. F. Becker, and D. B. Meier. 2004. Estimating wolf densities in forested areas using network sampling of tracks in snow. Wildlife Society Bulletin 32: 938-947.

Poole, K. G. 1995. Spatial organization of a lynx population. Canadian Journal of Zoology 73: 632-641.

Rosatte, R. 2011. Presence of mammals in Ontario, Canada, verified by trail camera photographs between 2008 and 2010. Canadian Field Naturalist 125: 193-199.

Schmidt, K., and R. Kowalczyk. 2006. Using scent-marking stations to collect hair samples to monitor Eurasian lynx populations. Wildlife Society Bulletin 34: 462-466.
Slough, B. G., and G. Mowat. 1996. Population dynamics of lynx in a refuge and interactions between harvested and unharvested populations. Journal of Wildlife Management 60: 946-961.

Squires, J. R., K. S. McKelvey, and L. F. Ruggiero. 2004. A snow-tracking protocol used to delineate local lynx, Lynx canadensis, distributions. Canadian Field-Naturalist 118: 583-589.

Squires, J. R., L. E. Olson, D. L. Turner, N. J. DeCesare, and J. A. Kolbe. 2012. Estimating detection probability for Canada lynx, Lynx canadensis, using snow-track surveys in the northern Rocky Mountains, Montana, USA. Wildlife Biology 18: 215-224.

Vashon, J. H., A. L. Meehan, W. J. Jakubas, J. F. Organ, A. D. Vashon, C. R. McLaughlin, G. J. Matula, Jr., and S. M. Crowley. 2008. Spatial ecology of a Canada lynx population in northern Maine. Journal of Wildlife Management 72: 1479-1487.

Zielinski, W. J., and T. E. Kucera. (Editors). 1995. American Marten, Fisher, Lynx, and Wolverine: Survey Methods for Their Detection. General Technical Report PSW-GTR-157. Pacific Southwest Research Station, Forest Service, U.S. Department of Agriculture, Albany, California.

Supplementary video available at:

http://www.canadianfieldnaturalist.ca

Received 11 July 2013

Accepted 9 September 2013 